\title{
Preço pago pelo consumidor de carne bovina nas diferentes regiões econômicas do Rio Grande do Sul, Brasil
}

\author{
Price paid by beef meat consumers from different economic regions of Rio Grande do Sul, Brazil
}

\author{
Vicente Celestino Pires Silveira ${ }^{\mathrm{I}}$ João Garibaldi Almeida Viana ${ }^{\mathrm{II}}$ Carlos Werner Júnior ${ }^{\mathrm{II}}$
}

\section{RESUMO}

O Estado do Rio Grande do Sul apresenta inúmeras diferenças no aspecto geográfico-econômicoambiental. No presente trabalho, considera-se a divisão regional proposta por ALONSO et al. (1994), a qual apresenta o Estado dividido em três regiões: metade sul, metade norte e nordeste. Na metade sul, a economia é baseada no setor primário, tendo a pecuária, como principal produto. A metade norte tem sua economia baseada na agricultura e a região nordeste caracteriza-se pela presença de vários setores industriais, com grandes concentrações urbanas. Sabe-se que o consumo é influenciado pela idade, renda, nível de educação, padrão de mobilidade e gosto dos consumidores. O objetivo, neste trabalho, foi verificar o comportamento do preço de diferentes cortes de carne bovina, em nível de consumidor, nas três regiões econômicas do Estado. A pesquisa caracterizou-se por um levantamento mensal em supermercados, durante os anos agrícolas 2006/2007 e 2007/2008, do preço de diferentes cortes de carne bovina em onze cidades. Os menores e os maiores preços da carne bovina verificados nas regiões metade Sul e nordeste, respectivamente, decorrem provavelmente do fato de que uma é a região produtora e a outra principal consumidora. Outro resultado importante é que as maiores variações, no preço dos cortes, ocorreram também nessas regiões. Portanto, num cenário em que a demanda é maior que a oferta, essas regiões parecem ser as primeiras a receberem o impacto nos preços da carne bovina.

Palavras-chave: economia regional, desigualdades regionais, cortes de carne bovina.

\section{ABSTRACT}

The State of Rio Grande do Sul presents various situations considering geographical, economical and environmental aspects. This study considers the regional division suggested by ALONSO et al. (1994): Southern half, Northern Half and Northeast. The primary sector is the base of Southern half economy and livestock production is its main product. The Northern half has crop production as its main economical resource, while the Northeast is characterized by the presence of various industrial sectors and large urban concentration. Consumer preferences are directly influenced by age, income, level of education, patterns of mobility and personal taste. The aim of this study was to verify price behaviour of different beef cuts. The research was done through a monthly data collection in supermarkets, during the periods of 2006/ 2007 and 2007/2008, considering the price of different beef cuts in eleven cities. The lowest and highest prices of beef cuts were verified in the Southern half and in the Northeast, respectively, which is probably due to the fact that one is the main producer and the other is the main consumer. Another important result is that the highest price variation in beef cuts also happened in these regions. Thus, when there is a higher demand than supply, the first to receive these impact on price are these regions.

Key words: regional economy, regional differences, beef cuts.

\section{INTRODUÇÃO}

O agronegócio é visto como a cadeia produtiva que envolve desde a fabricação de insumos, passando pela produção nos estabelecimentos agropecuários e pela sua transformação, até o seu consumo (GASQUES et al., 2004). No caso da bovinocultura de corte, existem basicamente quatro

'Departamento de Educação Agrícola e Extensão Rural, Universidade Federal de Santa Maria (UFSM), Prédio 44, 97105-900, Santa Maria, RS, Brasil. E-mail: vicentesilveira@smail.ufsm.br. Autor para correspondência.

IICurso de Pós-graduação em Agronegócio, Universidade Federal do Rio Grande do Sul (UFRGS), Porto Alegre, RS, Brasil.

IIIAssociação Riograndense de Empreendimentos de Assistência Técnica e Extensão Rural (EMATER)/Associação Sulina de Crédito e Assistência Rural (ASCAR), Porto Alegre, RS, Brasil. 
elos de processamento nessa cadeia: insumos, agropecuária (produtores), indústria (frigoríficos), distribuição/varejo. A cadeia é formada pelo setor montante da produção (indústrias produtoras de insumos tecnológicos e creditícios), o produtor rural e pelo setor jusante da produção (indústrias frigoríficas, curtumes, atacadistas, varejistas e consumidores finais.

Em dois pontos dessa cadeia, os preços do produto são públicos: o preço de venda dos animais pelo produtor e o de compra da carne pelos consumidores. No primeiro ponto, os preços podem ser obtidos diretamente junto aos frigoríficos, na Internet ou nos meios de comunicação. Quanto ao preço de compra pelos consumidores, conforme o código de defesa do consumidor, esses estão afixados em lugares de fácil visualização, nos diferentes locais de comercialização (VIANA\& SILVEIRA, 2007).

Sabe-se que o consumo é largamente influenciado pela idade, renda, nível de educação, padrão de mobilidade e gosto dos consumidores. Identificar fatores que influenciam a compra e tomada de decisão ajuda a compreendê-los e, consequentemente, atendê-los melhor. O papel das organizações é satisfazer as necessidades e desejos dos consumidores, compreendendo como eles percebem, aprendem e tomam suas decisões (MAZZUCHETTI \& BATALHA, 2004).

Como a cadeia é desarticulada e os supermercados são os responsáveis pela distribuição da grande maioria do produto ao consumidor (TELLECHEA, 2001), de uma forma geral, são eles que estabelecem as regras na cadeia da carne bovina e têm um papel muito significativo na definição dos preços praticados em todos os segmentos dessa cadeia. Essa afirmativa está baseada no fato de que o consumidor é o regulador de preços. A elevação do preço do produto ao consumidor final, imediatamente se reflete na redução ou, até mesmo, na estagnação das vendas. $\mathrm{O}$ consumidor é sensível ao aumento de preços e, como eles mantêm uma relação muito próxima dos supermercados, estes repassam os efeitos da "ponta" para os demais elos da cadeia produtiva (RIO GRANDE DO SUL, 2003).

Especificamente no caso do aumento na renda da população, essa provoca o aumento no consumo de carne bovina. Segundo NOVAES et al. (2007), esse fato ocorre, quando a renda varia até 15 salários mínimos. No entanto, ao se observar a faixa de renda maior do que 15 salários mínimos, a aquisição de carne bovina apresenta queda.

Ao considerarem consumidores de carne bovina, MAZZUCHETTI \& BATALHA (2004) observam que fatores econômicos (preço e renda) continuam sendo importantes para a tomada de decisão dos consumidores, mas perdem cada vez mais espaço para os não econômicos (efeito saúde, segurança alimentar, conveniência, qualidade e palatabilidade).

O Estado do Rio Grande do Sul apresenta inúmeras diferenças no aspecto geográfico-econômicoambiental. Quando se afirma que o Rio Grande do Sul encontra-se hoje dividido entre metade norte e metade sul e que uma região é economicamente rica e a outra pobre, desconsidera-se todo um processo de concentração econômica que teve início no final do século XIX e intensificou-se ao longo do século XX (Tabela 1), culminando com uma concentração econômica, populacional e industrial em uma parte da metade norte - a região nordeste (BATISTA \& SILVEIRA, 2006). Nesse aspecto, o presente trabalho considera a divisão regional proposta por ALONSO et al. (1994), na qual o Estado pode ser dividido em três regiões: metade sul, metade norte e nordeste.

A metade sul é uma região caracteristicamente agrária, em que prevalecem grandes propriedades que desenvolvem, predominantemente, a pecuária e a orizicultura. A região norte é caracterizada por pequenas e médias propriedades, com produção ligeiramente diversificada, enquanto a região nordeste é caracterizada pela presença de vários setores industriais, com grandes concentrações urbanas, sendo constituída pelo eixo Porto-Alegre-Caxias do Sul e algumas localidades do entorno (ILHA et al., 2002).

Na metade sul, a economia é fundamentada, principalmente, no setor primário, tendo a pecuária como principal produto, desenvolvida a partir de uma criação extensiva. A produção de arroz irrigado, segundo principal produto, é altamente mecanizada. $\mathrm{O}$ setor industrial é atrelado ao setor primário, não sendo, desta forma, complemento econômico para o sistema produtivo. O setor terciário é altamente dependente do setor primário, característica de economias que não estão inseridas em regiões metropolitanas e/ou regiões com forte industrialização. A metade norte, por sua vez, possuía menor importância econômica no inicio do século XX, além da menor parcela da população do Estado, com uma economia baseada na agricultura. Aos poucos, a produção agrícola diversificada foi competindo em espaço físico com a monocultura das lavouras de grãos, principalmente, soja e trigo. $\mathrm{Na}$ medida em que ocorre o fortalecimento do comércio e indústria no nordeste do Estado, uma grande parcela da população de outras regiões se desloca para essa área em busca de oportunidades de emprego e renda. Concomitantemente à concentração populacional e industrial, ocorre também uma concentração econômica na região nordeste, que passa a obter características 
próprias de desenvolvimento, baseando-se, principalmente, na indústria (BATISTA \& SILVEIRA, 2006).

A partir das diferenças de desenvolvimento econômico e social em torno das diferentes regiões do Estado, torna-se relevante estudar os preços de carne bovina em nível de varejo nessas localidades, devido à importância do perfil e gastos do consumidor na transmissão dos preços praticados em nível de produtor. Da mesma forma, verificam-se a carência de pesquisas cujo objetivo seja a análise de preços ao consumidor, comparando-os em regiões particularmente ofertantes e demandantes de carne bovina. Por fim, levanta-se a seguinte questão: Há diferenças nos preços pagos pelo consumidor de carne bovina nas três principais regiões econômicogeográficas do Rio Grande do Sul?

Nesse sentido, o objetivo, neste trabalho, foi o de verificar o comportamento do preço de diferentes cortes de carne bovina, em nível de consumidor, nas três regiões econômicas do Rio Grande do Sul: metade sul, metade norte e nordeste.

\section{MATERIAL E MÉTODOS}

A pesquisa caracterizou-se por um levantamento mensal em supermercados, durante os anos agrícolas 2006/2007 e 2007/2008, do preço de diferentes cortes de carne bovina em onze cidades do Rio Grande do Sul. Os dados foram coletados pela EMATER-RS, por meio do convênio UFSM/EMATER com apoio do Centro Integrado de Ensino Pesquisa e Extensão Rural-CIEPER. As cidades de Alegrete, Dom Pedrito, Santa Maria e Pelotas representam a região metade sul (RMS). A região metade norte (RMN) é representada por Erechim, Ijuí, Santa Rosa e Vacaria, enquanto Caxias do Sul, Porto Alegre e Santa Cruz do Sul representam a região nordeste (RN).

Os cortes "agulha” e "paleta” representaram o dianteiro na carcaça, como cortes do costilhar, a “costela” e o "vazio”, enquanto que "alcatra”, "chuleta”, “coxão de dentro”, “coxão de fora”, "maminha” e "picanha” representaram o traseiro na carcaça. A partir do trabalho de VIANA \& SILVEIRA (2007), verifica-se que esses cortes representam, respectivamente: $57,24 \%(21,98 / 38,40)$ do dianteiro, $56,25 \%(7,82 / 13,90)$ do costilhar e 42,37\% $(20,21 / 47,70)$ do traseiro.

A verificação dos dados foi feita por meio da análise de variância, utilizando-se o programa NCSS 6.0 (NCSS, 1995). Na Análise de Variância (ANOVA), o objetivo é analisar as diferenças entre as médias de grupos, a partir de uma análise de variação dos dados entre os grupos. A ANOVA decompõe a variação dos dados devido aos grupos e a fatores não controlados. Essa análise é indicada para mais de dois grupos ou tratamentos (dados numéricos e categóricos), sendo que a significância das variações é testada pela estatística $F$. A finalidade principal da ANOVAé apontar se um grupo é, estatisticamente, diferente do outro. Se a hipótese nula é rejeitada, a um determinado nível de significância, sabe-se então que existe, pelo menos, uma das médias de um grupo diferente de outra. Para se determinar qual ou quais grupos ou tratamentos diferem estatisticamente, utilizam-se testes para identificar as diferenças mínimas significativas (LOPES et al., 2007). O delineamento estatístico utilizado foi de um fatorial 2 X 3, visando a verificar a magnitude dos efeitos do ano agrícola, da região e de sua interação, testados através do teste $\mathrm{F}$, em nível de $5 \%$. A comparação entre médias dos fatores principais foi realizada pelo teste de Tukey a 5\% de probabilidade, pois a interação ano versus região não foi significativa para nenhum dos cortes analisados.

\section{RESULTADOS E DISCUSSÃO}

O efeito de ano é claramente percebido na tabela 2. O maior aumento percentual entre anos foi o

Tabela 1 - Área, PIB Total e PIB por área das regiões do Rio Grande do Sul.

\begin{tabular}{|c|c|c|c|c|c|}
\hline \multirow{2}{*}{ Região } & \multicolumn{2}{|c|}{----------------Área---------------- } & \multicolumn{2}{|c|}{-----------------PIB Total----------------- } & \multirow{2}{*}{$\begin{array}{l}\text { PIB/Área } \\
\left(\mathrm{R} \$ \mathrm{Km}^{-2}\right)\end{array}$} \\
\hline & $\mathrm{Km}^{2}$ & $\%$ & $\mathrm{R} \$$ & $\%$ & \\
\hline Nordeste & $25.310,20$ & 8,98 & 57.959.657.158,22 & 53,44 & $2.289 .972,31$ \\
\hline Norte & $93.385,70$ & 33,13 & $30.949 .073 .265,25$ & 28,53 & $311.411,27$ \\
\hline Sul & $150,281,20$ & 53,32 & 19.562.007.479,04 & 18,03 & 130.169,36 \\
\hline Lagoa dos Patos & $10.049,62$ & 3,57 & - & - & - \\
\hline Lagoa Mirim & $2.811,53$ & 1,00 & - & - & - \\
\hline Total RS & $281.838,25$ & 100 & 108.470.737.902,52 & 100 & - \\
\hline
\end{tabular}

Fonte: BATISTA \& SILVEIRA (2006).

Ciência Rural, v.39, n.4, jul, 2009. 
da costela minga $(26,85 \%)$ e o menor reajuste foi no corte coxão de fora (20,56\%). Questões conjunturais podem ter influenciado nessa variação de preço entre anos. Primeiro, a escassez de animais para o abate, em decorrência da mudança de ciclo da pecuária de corte, após um período de preços desfavoráveis aos criadores. Isso estimulou o abate de matrizes, resultando na diminuição de animais para engorda. Segundo, retenção de fêmeas para a produção de bezerros, devido à valorização destes também conduz a uma menor oferta de animais para o abate. Outro fator é que muitos produtores do Brasil central preferiram arrendar parte das terras para usinas de álcool ou plantar diretamente a cana-de-açúcar, transformando muitos pastos em canaviais (PROCON-SP, 2008). No caso do Rio Grande do Sul o aumento da área dedicada à cultura de grãos e à silvicultura também reduziram a área dedicada à pecuária de corte.

O preço médio dos diferentes cortes por região estão na tabela 2 . Ao observarmos os dados, de uma maneira geral, os maiores preços são observados na RN e os menores na RMS. Uma possível explicação, para os menores preços na RMS, é a concentração da produção de bovinos de corte (SANTOS et al., 2007),

Tabela 2 - Preço médio do quilo dos cortes da carcaça bovina nas diferentes regiões econômicas do Rio Grande do Sul, nos anos agrícolas 2006/07 e 2007/08.

\begin{tabular}{|c|c|c|c|c|c|}
\hline \multirow{2}{*}{$\begin{array}{l}\text { Fator } \\
\text { Corte }\end{array}$} & \multicolumn{2}{|c|}{----------------Ano Agrícola--------------- } & \multicolumn{3}{|c|}{ 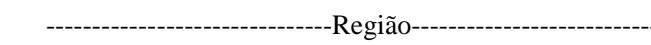 } \\
\hline & 2006/07 & $2007 / 08$ & RMS & RMN & $\mathrm{RN}$ \\
\hline Dianteiro & & & & & \\
\hline Agulha & $\begin{array}{l}4,58^{\mathrm{B}} \\
( \pm 0,08)\end{array}$ & $\begin{array}{l}5,61^{\mathrm{A}} \\
( \pm 0,08)\end{array}$ & $\begin{array}{l}4,66^{\mathrm{b}} \\
( \pm 0,11)\end{array}$ & $\begin{array}{l}5,44^{\mathrm{a}} \\
( \pm 0,09)\end{array}$ & $\begin{array}{l}5,19^{\mathrm{ab}} \\
( \pm 0,16)\end{array}$ \\
\hline Paleta & $\begin{array}{l}4,84^{\mathrm{B}} \\
( \pm 0,07)\end{array}$ & $\begin{array}{l}5,96^{\mathrm{A}} \\
( \pm 0,07)\end{array}$ & $\begin{array}{l}5,14^{\mathrm{b}} \\
( \pm 0,09)\end{array}$ & $\begin{array}{l}5,27^{\mathrm{b}} \\
( \pm 0,08)\end{array}$ & $\begin{array}{l}5,78^{\mathrm{a}} \\
( \pm 0,09)\end{array}$ \\
\hline Costilhar & & & & & \\
\hline Costela & $\begin{array}{l}6,07^{\mathrm{B}} \\
( \pm 0,11)\end{array}$ & $\begin{array}{l}7,70^{\mathrm{A}} \\
( \pm 0,11)\end{array}$ & $\begin{array}{l}6,72^{\mathrm{a}} \\
( \pm 0,14)\end{array}$ & $\begin{array}{l}7,01^{\mathrm{a}} \\
( \pm 0,14)\end{array}$ & $\begin{array}{l}6,94^{\mathrm{a}} \\
( \pm 0,16)\end{array}$ \\
\hline Vazio & $\begin{array}{l}7,50^{\mathrm{B}} \\
( \pm 0,12)\end{array}$ & $\begin{array}{l}9,55^{\mathrm{A}} \\
( \pm 0,12)\end{array}$ & $\begin{array}{l}7,88^{\mathrm{b}} \\
( \pm 0,14)\end{array}$ & $\begin{array}{l}9,27^{\mathrm{a}} \\
( \pm 0,14)\end{array}$ & $\begin{array}{l}8,57^{\mathrm{ab}} \\
( \pm 0,16)\end{array}$ \\
\hline Traseiro & & & & & \\
\hline Alcatra & $\begin{array}{l}10,44^{\mathrm{B}} \\
( \pm 0,16)\end{array}$ & $\begin{array}{l}12,86^{\mathrm{A}} \\
( \pm 0,16)\end{array}$ & $\begin{array}{l}10,45^{\mathrm{c}} \\
( \pm 0,19)\end{array}$ & $\begin{array}{l}11,40^{\mathrm{b}} \\
( \pm 0,18)\end{array}$ & $\begin{array}{l}13,11^{\mathrm{a}} \\
( \pm 0,21)\end{array}$ \\
\hline Coxão de Dentro & $\begin{array}{l}9,64^{\text {B }} \\
( \pm 0,12)\end{array}$ & $\begin{array}{l}11,66^{\mathrm{A}} \\
( \pm 0,12)\end{array}$ & $\begin{array}{l}9,67^{\mathrm{c}} \\
( \pm 0,15)\end{array}$ & $\begin{array}{l}10,83^{\mathrm{b}} \\
( \pm 0,14)\end{array}$ & $\begin{array}{l}11,45^{\mathrm{a}} \\
( \pm 0,16)\end{array}$ \\
\hline Coxão de Fora & $\begin{array}{l}8,56^{\text {В }} \\
( \pm 0,13)\end{array}$ & $\begin{array}{l}10,32^{\mathrm{A}} \\
( \pm 0,13)\end{array}$ & $\begin{array}{l}8,94^{\mathrm{b}} \\
( \pm 0,17)\end{array}$ & $\begin{array}{l}9,09^{\mathrm{b}} \\
( \pm 0,14)\end{array}$ & $\begin{array}{l}10,28^{\mathrm{a}} \\
( \pm 0,17)\end{array}$ \\
\hline Maminha & $\begin{array}{l}10,37^{\text {в }} \\
( \pm 0,21)\end{array}$ & $\begin{array}{l}12,83^{\mathrm{A}} \\
( \pm 0,21)\end{array}$ & $\begin{array}{l}11,23^{b} \\
( \pm 0,25)\end{array}$ & $\begin{array}{l}11,13^{\mathrm{b}} \\
( \pm 0,24)\end{array}$ & $\begin{array}{l}12,45^{\mathrm{a}} \\
( \pm 0,30)\end{array}$ \\
\hline Picanha & $\begin{array}{l}14,67^{\text {в }} \\
( \pm 0,31)\end{array}$ & $\begin{array}{l}17,73^{\mathrm{A}} \\
( \pm 0,31)\end{array}$ & $\begin{array}{l}14,02^{b} \\
( \pm 0,38)\end{array}$ & $\begin{array}{l}15,24^{\mathrm{b}} \\
( \pm 0,36)\end{array}$ & $\begin{array}{l}19,34^{\mathrm{a}} \\
( \pm 0,42)\end{array}$ \\
\hline Chuleta & $\begin{array}{l}7,44^{\mathrm{B}} \\
( \pm 0,09)\end{array}$ & $\begin{array}{l}9,24^{\mathrm{A}} \\
( \pm 0,09)\end{array}$ & $\begin{array}{l}7,38^{\mathrm{c}} \\
( \pm 0,12)\end{array}$ & $\begin{array}{l}7,96^{\mathrm{b}} \\
( \pm 0,11)\end{array}$ & $\begin{array}{l}9,52^{\mathrm{a}} \\
( \pm 0,13)\end{array}$ \\
\hline
\end{tabular}

Letras diferentes (maiúsculas para efeito ano agrícola e minúsculas para efeito região) indicam diferença estatística na linha, pelo teste de Tukey $(\mathrm{P}<0,05)$.

Ciência Rural, v.39, n.4, jul, 2009. 
bem como dos principais frigoríficos, além de que a região apresenta o menor PIB per capita entre as regiões do Rio Grande do Sul (BATISTA \& SILVEIRA, 2006).

Ao se observarem os resultados do cortes do dianteiro, verifica-se que a RMS apresenta os menores preços. O maior preço do corte paleta, na $\mathrm{RN}$, pode decorrer de que esse é bastante consumido como "carne de panela”, assim tal corte apresenta elevada procura como consequência da alta densidade demográfica da região, o que conduz a um aumento de procura, elevando, dessa forma, o preço.

Quanto aos preços pagos pelos cortes do costilhar, verifica-se que a costela foi o único corte que não apresentou diferença significativa no preço entre as diferentes regiões do Estado. Esse fato, provavelmente, está ligado, diretamente, à tradição do gaúcho de que “ no churrasco não pode faltar a costela”. Outro fator a ser considerado é que esse corte não apresenta produto substituto no mercado, ao contrário dos demais cortes bovinos que podem ser substituídos por carne de frango ou suíno. O alto valor pago pelo vazio na RMN decorre, provavelmente, da escolha regional desse corte para acompanhar a costela, como carne sem osso no churrasco, pois seu preço é inferior, quando comparado ao do corte maminha e picanha, visto que a renda, nessa região, é inferior à da RN (BATISTA \& SILVEIRA, 2006).

Todos os cortes componentes do traseiro apresentam preços significativamente mais elevados na RN. A região caracteriza-se por ser a que possui a maior concentração populacional e maior PIB per capita, fatores ligados, diretamente, à demanda de carne bovina, além de que, quando a renda for inferior a 15 salários mínimos, um aumento na renda da população, como o ocorrido nos anos de 2006 à 2008, provoca o aumento no consumo de carne bovina (NOVAES et al., 2006). Por outro lado, a produção de bovinos na região é muito baixa, assim, a carne consumida provém das outras regiões. Esse fato da produção local pode ser também considerado para explicar o porquê de alguns cortes serem, significativamente, mais caros na RMN, quando comparado com a RMS.

Na figura 1, observam-se os valores mínimos, máximos e o percentual de diferença dos preços dos cortes nos dois anos de coletas de dados. De acordo com os dados do PROCON-SP (2008), o comportamento dos preços da carne bovina, tanto de primeira quanto de segunda, nas pesquisas da cesta básica, em 2007, demonstrou oscilações de pequeno porte na maioria dos meses, porém, a partir de outubro de 2007, as altas foram mais expressivas. Na avaliação realizada em junho de 2008, o preço da carne bovina apresenta variações positivas de preço desde o mês de março de 2008, tendo o preço da carne de segunda apresentado, em junho, sua maior variação positiva mensal, em dez anos. As diferenças entre valores mínimo e máximo, no período coletado, ratificam as afirmações realizadas. As maiores variações ocorreram nas regiões $\mathrm{RMN}$ e $\mathrm{RN}$, regiões basicamente consumidoras, ocorrendo menor variação na RMS, região fundamentalmente produtora.

De acordo com ZEN (2008), o mercado europeu concentra suas compras nos cortes traseiros: filé mignon, alcatra, contrafilé, coxão mole (coxão de dentro) e coxão duro (coxão de fora), os demais ficam para o mercado interno. Como o frigorífico não pode tirar apenas esses cortes da carcaça, é obrigado a comercializar a picanha, maminha e outros cortes no mercado interno a preços que, por vezes, são inferiores ao valor que precisariam ter para cobrir seus custos e manter suas margens. A diferença vem das exportações para a Europa, sendo o consumidor brasileiro beneficiado pelas promoções do varejo dos cortes não exportados, o que auxilia na explicação da variação, entre meses, do preço de determinados cortes no mercado interno. Apesar do bom desempenho do setor exportador, o segmento de carnes continuou sentindo os efeitos das restrições comerciais impostas por alguns países, por ocasião dos problemas sanitários enfrentados pelo Brasil, ao longo de 2006 (PROCONSP, 2008).

O Rio Grande do Sul caracteriza-se como estado exportador de carne de qualidade por ter animais de raças européias em seu rebanho, ao contrário do resto do Brasil. Por outro lado, o rebanho gaúcho compete fortemente por espaço, nos últimos anos, com a lavoura de soja e, mais recentemente, com o setor florestal. Portanto, a oferta de carne bovina está cada vez mais pressionada e a demanda interna e externa continua a crescer. VIANA et al. (2008) verificaram que os cortes filé mignon e costela apresentaram comportamento de preços distintos dos demais, obtendo elevação, principalmente, no período pós 1996, comportamento esse influenciado, no caso do filé mignon, pelo crescimento das exportações de cortes especiais, e no caso da costela, pelo aumento do poder aquisitivo e do consumo de carnes de churrasco, além de o corte não apresentar produto substituto para comercialização.

\section{CONCLUSÕES}

Os menores e os maiores preços verificados nas regiões metade sul e nordeste, respectivamente, decorrem talvez do fato de que uma é a região produtora 


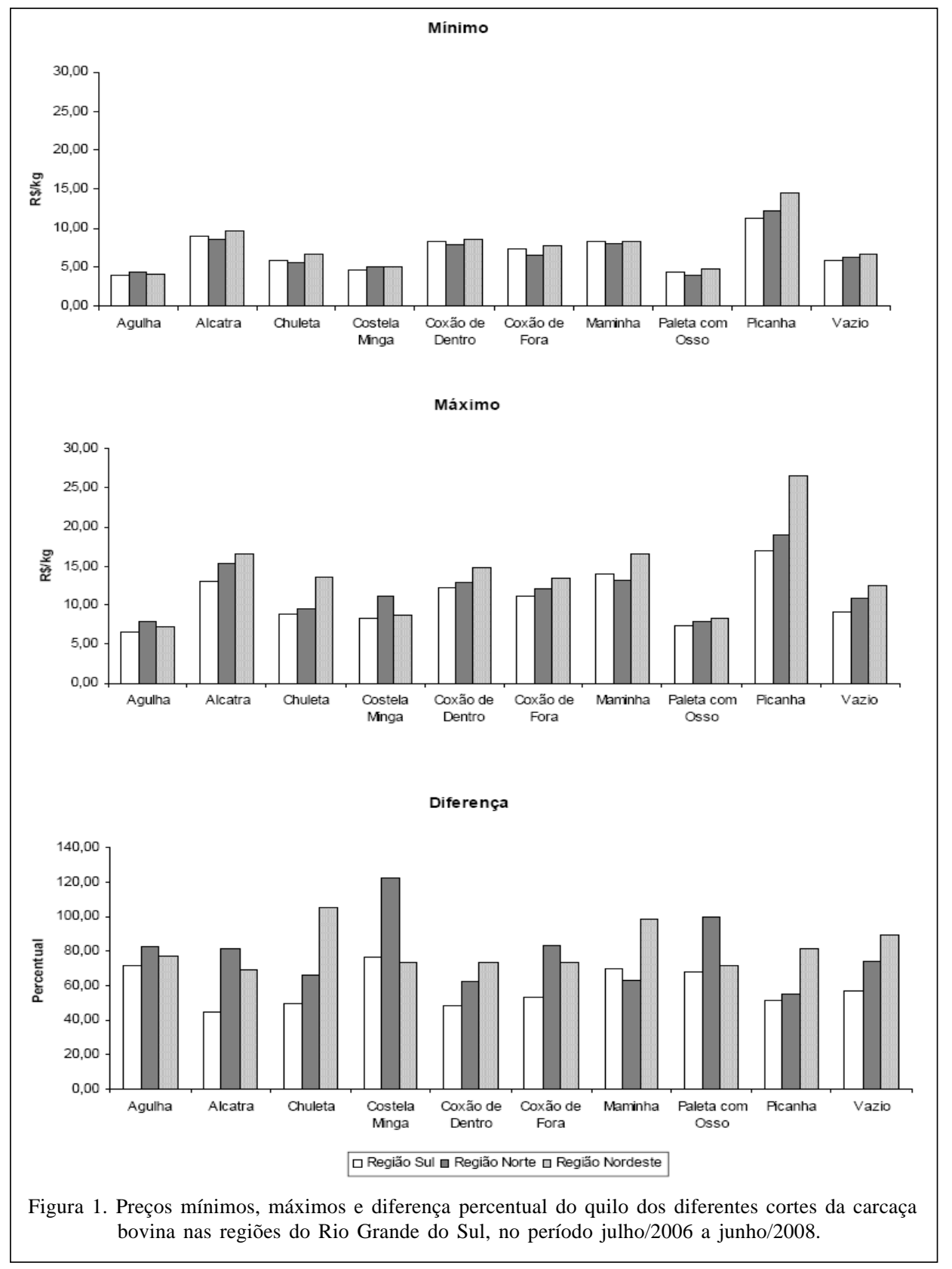

e ao outra a principal consumidora de carne bovina. Outro resultado importante é que as maiores variações ocorreram nas regiões RMN e RN, portanto, em um cenário de demanda maior que a oferta, essas regiões parecem ser as primeiras a receberem o impacto nos preços da carne bovina. Constata-se que o comportamento dos preços de carne bovina, no varejo do Rio Grande do Sul, está, fundamentalmente, vinculado ao perfil do consumidor final. Dessa forma, produtores rurais e indústrias frigoríficas podem desenvolver ações conjuntas que busquem determinar e ofertar produtos, conforme as preferências regionais dos consumidores a fim de agregar valor aos seus processos produtivos.

A partir dos resultados do presente estudo, evidencia-se um novo campo de pesquisas na cadeia da carne bovina que busca estabelecer o comportamento dos preços, em nível de consumidor, nas diferentes regiões econômicas do Rio Grande do Sul. Futuras pesquisas devem dar maior atenção a um levantamento histórico de dados em um período superior a dois anos para determinar, de forma mais 
precisa, os efeitos conjunturais e estruturais dessa cadeia nos preços praticados e, consequentemente, na oferta e demanda de carne bovina.

\section{REFERÊNCIAS}

ALONSO, J.A.F. et al. Crescimento econômico da Região Sul do Rio Grande do Sul: causas e perspectivas. Porto Alegre: FEE, 1994. 227p.

BATISTA, I.M.; SILVEIRA, V.C.P. Influência das desigualdades econômicas regionais no setor agropecuário do Rio Grande do Sul. Revista Extensão Rural, Santa Maria, Ano XIII, p.6092, 2006.

GASQUES, J.G., et al. Desempenho e crescimento do agronegócio no Brasil. Brasília: Instituto de Pesquisa Econômica Aplicada (IPEA), 2004. Texto para Discussão, 1009. 43p. Disponível em: <http://www.ipea.gov.br>. Acesso em: 18 mar. 2005.

ILHA, et al. Desigualdades regionais no Rio Grande do Sul: o caso da metade sul. In: ENCONTRO DE ECONOMIA GAÚCHA PUCRS/ FEE, 2002, Porto Alegre. Anais... Porto Alegre: FEE, 2002. (CD-ROOM).

LOPES, L.F.D. et al. Caderno de estatística. 2.ed. Santa Maria: UFSM, 2007. 201p.

MAZZUCHETTI, R.N.; BATALHA, M.A. O comportamento do consumidor em relação ao consumo e às estruturas de comercialização da carne bovina na região de Amerios/PR. Revista Varia Scientia, v.04, n.08, p.25-43, 2004.

NCSS 6.0. Statistical system for Windows. Number Cruncher Statistical Systems. Kaysville, Utah, 1995. 1558p.

NOVAES, A.L. et al. Efeito do nível de escolaridade no consumo de carne bovina e hortaliças no Brasil. In: CONGRESSO
BRASILEIRO DE ECONOMIA E SOCIOLOGIA RURAL, 45., 2007, Londrina. Anais... Brasília: SOBER, 2007. (CDROOM)

PROCON-SP. Pesquisa cestas básica anuais. Disponível em: <http://www.procon.sp.gov.br/categoria.asp?id=462>. On line. Acessado em: 21 Out. 2008.

RIO GRANDE DO SUL. Assembléia Legislativa. CPI DAS CARNES Relatório Final. Porto Alegre, 2003. 764 p. Disponível em: <http://www.al.rs.gov.br $>$. On line. Acessado em: 15 jun. 2004.

SANTOS, D.V. et al. Vacinação do rebanho bovídeo gaúcho contra a febre aftosa em janeiro de 2007. A Hora Veterinária, Porto Alegre, v.27, n.159, p.13-16, 2007.

TELLECHEA, F. Análise dos custos de transação no setor industrial da cadeia produtiva de carne bovina no Rio Grande do Sul. 2001. 98f. Dissertação (Mestrado em Economia Rural) - Universidade Federal do Rio Grande do Sul, Porto Alegre, RS.

VIANA, J.G.A. et al.. Evolução dos Preços históricos da bovinocultura de corte do Rio Grande do Sul: tendência e comportamento dos preços em nível de produtor e consumidor. In: CONGRESSO BRASILEIRO DE ECONOMIA E SOCIOLOGIA RURAL, 46., 2008, Rio Branco. Anais... Brasília: SOBER, 2008. (CD-ROOM)

VIANA, J.G.A.; SILVEIRA, V.C.P. A relação entre o preço pago pelo consumidor de carne bovina em Santa Maria e o recebido pelo produtor de gado de corte no Rio Grande do Sul, Brasil. Ciência Rural, v.37, n.4, p.1122-1127, 2007. Disponível em: <http:// www.scielo.br/scielo.php?script=sci_arttext $\&$ pid $=$ S0103$84782007000400033 \& \operatorname{lng}=$ pt\&nrm=iso $>$. Doi: $10.1590 / S 0103-$ 84782007000400033 .

ZEN, S. de. Os interessados na carne bovina do Brasil. Disponível em: http://www.paginarural.com.br/artigos_detalhes.php. On line. Acesso em: 12 abr. 2008. 